\title{
Impact of the Organizational Culture on Creative Behavior: A Field Study on a Sample of Commercial Banks Operating in Jordan
}

\author{
Dr. Hazem Khaled Shehadeh, Assistant Professor
}

Head of Business Administration Department,

Faculty of Economics and Administrative Sciences, Zarqa University, Jordan

doi: 10.19044/esj.2016.v12n25p214 URL:http://dx.doi.org/10.19044/esj.2016.v12n25p214

\begin{abstract}
This study aims to analyze the impact of the organizational culture on the creative behavior by taking a field study on a sample of commercial banks operating in Jordan. To achieve this objective, a questionnaire which included 30 items was built and developed. The reliability and the sincerity of the tool were tested. Then, the questionnaire used on a sample study of 250 employees in the commercial banks operating in Jordan was selected at random. This was done using a stratified random sample method. A number of findings found in this study include the following: a. Rise in the means of the organizational culture dimensions which include work teams, ability to adapt, and the ability to innovate. It also includes the creative behavior dimensions such as problem solving, change susceptibility, and amplitude to contact. These results indicate that the employee's responses in the commercial banks operating in Jordan about the mentioned dimensions were positive. Also, this means that the evaluation level of these dimensions was high from their perspective. $\mathbf{b}$. Existence of a statistically significant impact at the significance level $(\alpha=$ $0.05)$, for the organizational culture dimensions which are work teams, ability to adapt, and ability to innovate, and on the creative behavior of the employees at the commercial banks operating in Jordan. The study, however, gave a number of conclusions and recommendations.
\end{abstract}

Keywords: Organizational culture, Creative behavior, Ability to adapt, change Susceptibility, Commercial banks, Jordan

Organizations are considered as an important vital tool in the contemporary human societies. Human resource constitutes the effective cornerstone in these organizations through the various patterns of the interactions and behaviors. Thus, this was performed through judgment on the efficiency and effectiveness of these organizations. 
As there is a change, development, and innovation in addition to the search on further efficiency and innovation of the modern management organizations attributes which are looking for the leadership and excellence in the emergence of the smart organizations, so became the subject of organizational culture of the important subjects. Its share of attention was taken by the senior management or by the researchers in various organizations, especially the banking sector.

In light of the foregoing, the organizational culture became a pillar of the pillars that is based on the change in the creative behavior among employees in the commercial banks. This is because of the overlap of different cultures to employees and customers. It also occurs due to the nature of those bank works that do not focus on the internal environment only, but the external environment also.

\section{Methodology}

\section{The Study Problem}

The organizational culture is considered as a cryptic dimension. However, it performs an active role in implementing many of the strategies of the enterprise, its structure, systems, control, and monitoring. The lack of the possibility of organizations of the institutional adaptation is due to the difference in the culture whether in the internal environment or the external environment. On one hand, the existence of a gap between the bank aspirations and the institutional reality is the needed drive element to perform its works (organizational culture). This works to achieve the desired results and bridge the gap between the bank aspirations and the reality as was reflected positively on the creative behavior on the other hand. Accordingly, the study problem aims to analyze the impact of the organizational culture on the creative behavior of the employees in the commercial banks operating in Jordan.

In light of the foregoing, the study problem can be expressed by answering the following questions:

- What is the application level of the organizational culture dimensions in the commercial banks from the perspective of their employees?

- What is the evaluation level of the employees in the commercial banks for the creative behavior dimensions?

- Is there a significant impact for the organizational culture on the creative behavior of the employees in the commercial banks operating in Jordan?

\section{The Study Importance} following:

Subsequently, the current study is gaining importance through the 
a. This study addressed a very important topic which is organizational culture. It is a relatively modern management concept which can be applied in business organizations in general and banks in particular.

b. This study was considered as an illumination for the cultural heritage of the institutional and intellectual enrichment of the concepts of the organizational culture and the creative behavior in the Arab library in general and Jordanian library in particular.

c. It is used for the analysis of the impact of the organizational culture on the creative behavior of the employees at the commercial banks operating in Jordan.

d. The findings of this study can be useful and serves as a good recommendation of the decision makers at the commercial banks operating in Jordan. Thus, it should be accurate and objective when choosing the organizational culture dimensions of the form in which it contributes to the improvement of the creative behavior of the mentioned banks. In addition, these banks play an active role in the success of the organizations in general and the banks in particular.

\section{The Study Objectives}

The study seek to achieve a number of objectives among which are the following:

a. To identify the philosophical framework for the concepts of the organizational culture and the creative behavior and nature of their relationship.

b. To identify the application level of the organizational culture at the commercial banks operating in Jordan.

c. To measure the impact of the organizational culture on the creative behavior of the employees at the commercial banks operating in Jordan.

d. To provide some of the necessary recommendations to the decision-makers at the commercial banks operating in Jordan.

\section{The Operational Definitions}

- Organizational Culture: The organizational culture represent the behavioral practices resulting from the individuals interactions between each other and that lead to a certain performance level in the organizations. Therefore, this culture is expressed from the set of values and beliefs, concepts and joint reflection methods in the framework of the work teams, the ability to innovate, and alongside with the ability to adapt.

a. Work Teams: This means a limited number of groups cooperating members under the different cultures in accordance with instructions and specific objectives which commensurate with the strategies of the Commercial Bank in reaching the objectives as fast as possible. 
b. The Ability to Innovate: This refers to the worker's ability to produce a new product despite the existence of Multi-culture within the organization.

c. The Ability to Adapt: This is a continuing dynamic process that contributes to change in behavior and the environment (natural and social) in such a way that it achieves the balance between the individual and his environment.

- Creative Behavior: This refers to the behaviour portrayed by the human resource in the workplace as a result of a series of the decisions which when taken by, begin to realize and analyze the position being present. Then information is collected, alternatives are evaluated, and the appropriate alternatives were chosen in order to adopt or reject a certain behavior or idea.

a. Solving the Problem: Refers to the employee's ability to discover the problems and develop the solutions to them in new ways during a specific period of time despite the dearth of information.

b Change Susceptibility: Refers to the extent of the employee willingness to discuss the work activities, obtain clarity from his superiors, and the possibility of the change through following new methods and ways at work.

c. Contact Amplitude: This expresses the available opportunity in front of the employee to transfer and interpret the incoming connection from the internal environment in the enterprise of the various departments and units. It also involves its ability to be expanded to include the parties of the external environment.

\section{The Study Model}

To achieve the study objectives, the researcher has adopted the default model shown in Figure (1) below. The model indicates the existence of two types of the variables. The first variable is the independent variable (organizational culture) which includes three dimensions: work teams, the ability to adapt, and the ability to innovate. The second variable is the dependent variable (creative behavior), which includes three dimensions: solving the problems, change susceptibility, and contact amplitude. 


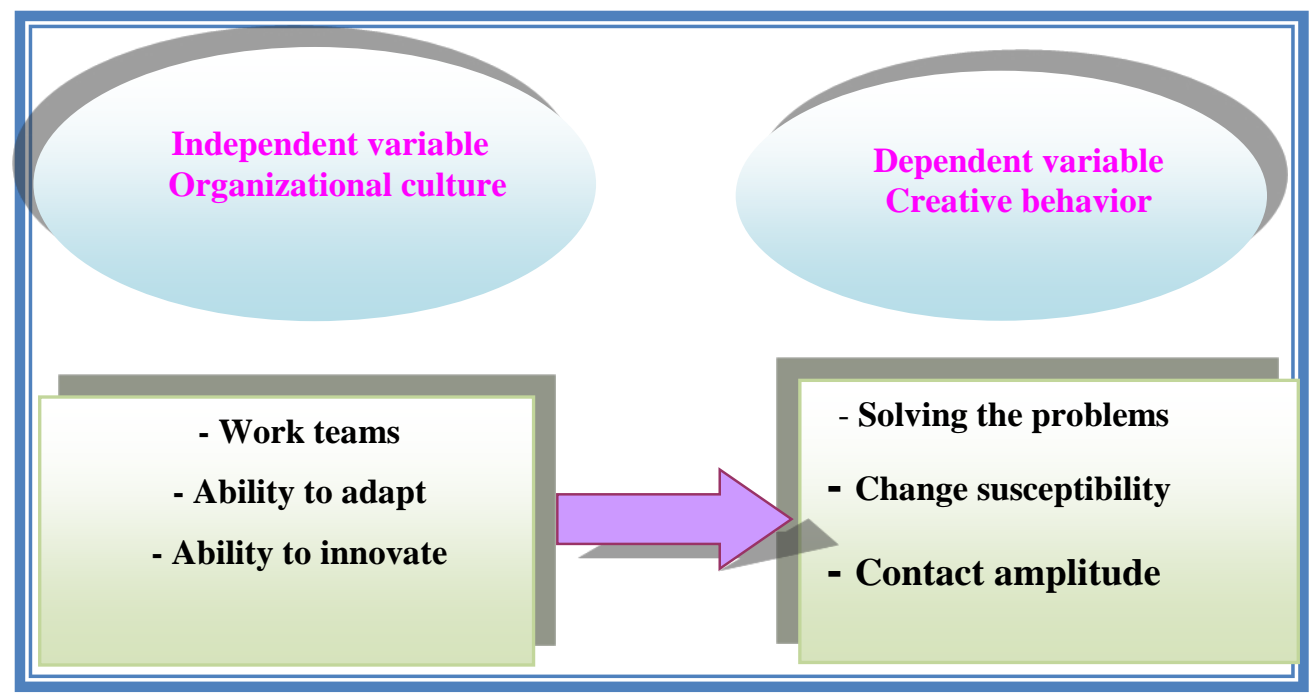

Source: Prepared by the researcher.

Figure 1. The Study Model

\section{The Study Hypotheses}

To achieve the study objectives, the researcher suggested the following hypothesis as a null form $\left(\mathrm{H}_{0}\right)$ :

Ho: There is no statistically significant impact at the significant level $(\alpha \leq 0.05$ ), for the organizational culture dimensions (work teams, the ability to adapt, and the ability to innovate), on the creative behavior of the employees at the commercial banks operating in Jordan.

Furthermore, the hypothesis is subdivided into three sub-hypotheses which are as follows:

Ho1: There is no statistically significant impact at the significant level ( $\alpha \leq 0.05$ ), for the organizational culture dimensions (work teams, the ability to adapt, and the ability to innovate), on solving the problems at the commercial banks operating in Jordan.

Ho2: There is no statistically significant impact at the significant level $(\alpha \leq 0.05$ ), for the organizational culture dimensions (work teams, the ability to adapt, and the ability to innovate), on change susceptibility in the commercial banks operating in Jordan.

Ho3: There is no statistically significant impact at the significant level $(\alpha \leq 0.05$ ), for the organizational culture dimensions (work teams, the ability to adapt, and the ability to innovate), on contact amplitude at the commercial banks operating in Jordan. 


\section{Literature review}

\section{Theoretical Framework}

\section{The Organizational Culture Concept}

The organizational culture is defined as a layout of the shared values, beliefs, and interactions in the organizational environment which forms the internal control and the human group present in the organization, and distinguishes it from the other organizations (Al-Emmyan, 2009).

Wheelen defined it as a set of the beliefs, expectations, and the values shared by the organization members. Shermerborn defined it as a system of the values and beliefs shared by the employees in the organization where this system is growing within the same organization. Kossen also defined it as the set of the values brought by the organization members (heads and subordinates) from the external environment to the internal environment for that organization (Al-Emmyan, 2009: 311).

Al-Faraj (2011) defined organizational culture as the behavioral practices arising from the interactions between individuals and that leads to a certain performance level in the organizations. It is the culture expressed from the set of the values and beliefs, concepts, and methods of common thinking between the old leaders and members of the organization. However, these are being taught to new members. Therefore, the organizational culture consists of the controlling of social values that help in achieving the integration of the organization parts.

In light of the foregoing, the organizational culture was usually formed which acquired the human resource of the behavioral patterns and technical skills, process, cognitive and ways of thinking, values, habits, and directions before they join the organization or the institution which they work in. Then, the organization confers on it the cultural pattern for the employees of its values and customs of their characteristics, concerns, policies, objectives, and its vision which determines the personality of the Organization. This was done to distinguish itself from other organizations.

\section{Functions of the Organizational Culture}

The functions of the organizational culture include the following:

a. Provide the organization and its employee's sensation of identity: The more we identify the ideas and values which prevail in the organization, the greater the employees' correlation with the organization's mission. Thus, this increases their feeling that they are a vital part of it.

b. Finding commitment of the company's mission: The people's thinking is usually limited as to the effects it has on them personally, or if they feel a strong affiliation to the organization by the general culture in control. The attention of the organization to which they belong is greater than their 
personal interests. Therefore, this means that the culture helps in reminding them that their organization is the most important thing for them.

c Supporting and clarifying the behavior standards in the organization: The culture is leading the actions and sayings of the employees, which clearly outlines what should be said or done in each case. Thus, this is achieved by the stability of the expected behavior of the individual at different times, and also the expected behavior of a number of the employees at the same time (Gerinberg \& Baron, 2004: 630).

\section{Characteristics of the Organizational Culture}

Consequently, there is no organization that its culture is similar to the culture of another organization, even if they operate in the same sector. There are many aspects of the culture which vary in the organizations culture. As such, every organization is trying to develop its culture. One aspect of the difference between the organizations is the organization age, its communications patterns, work systems and procedures, and the process of the exercise of power, style of leadership, values, and beliefs. One of the important characteristics of the organization culture is as follows (AlEmmyan, 2009: 314):

a. The regularity in the behavior and abiding by it: The result of the interaction between the organization members shows that they are using the language, terminology, phrases, and common rites related to the behavior in terms of the respect.

b. The standards: There are many behavior standards in relation to the size of work to be done (do not work very much, not very little).

c. Controlling values: There are fundamental values adopted by the organization, and it is expected that each member should adhere to it. They include: high quality, low rate of absences, and compliance to the regimes and instructions.

d. Philosophy: Each organization has its own policy in the relationship between the employees and the customers.

e. The rules: This is an instruction issued by the organization and it varies in severity from one organization to another. Also, the individual works in the organization according to the rules drawn for him.

f. The organizational climate: The organizational climate is a group of characteristics that characterize the internal environment in which the individuals works. Furthermore, it affects their values, their direction, and their perception, because it enjoys a high degree of stability and relative stability. In addition, the characteristics group include the organizational structure, leadership style, policies, procedures \& laws, and communication patterns, etc (Al-Emmyan, 2009: 315-316). 


\section{The Creative Behavior Concept}

The Creative behavior is defined as the behavior or the distinguished behave which is perpetrated by the individual or the group in the workplace. It does not necessarily result in the outcomes of new services and goods, where the behavior finally precedes creativity. This behavior is creative in itself when practiced by the individual for the first time in the organization (Al-Qaryouti, 2000).

Al-Qaryouti has indicated that creativity is the composite process which includes at least a mental element, emotional element, and a behavioral element. The mental element represents the creative thinking, which in turn generates the emotional sense, such as satisfaction or dissatisfaction. Then, it embodies the two previous elements themselves by which creative behavior appears to others in the form of outcomes. The creativity stops at the first or second stage and therefore does not show any behavior (Al-Qaryouti, 2000).

\section{Characteristics of the Creative Organizations}

The characteristics of the creative organizations can be identified through analyzing the organizational processes within the organization. Nevertheless, the most important of these indicators which is characterized by the creative organizations are as follows (Najem, 2007):

a. The creative organizations are what make creativity and innovation an essential source of achieving the competitive advantage.

b. Creativity is considered as a resource and a cause to distinguish it. This is in addition to its support of the leadership of the creativity by all physical and moral means.

c. The creative organizations are characterized by seeking to solidify an organizational culture based on the openness and its creativity within its strategic vision.

d. The creative organizations that are interested in the activities of the research and development and evaluation constantly are always trying to seize creative opportunities.

From the above, the researcher finds that the creative organizations are what make creativity to be an available project for all levels of the organization. Therefore, this is what rewards the creative behavior and expand its base within the organization.

Subsequently, creativity cannot always be appearing through the appointment of creative persons in the organizations because some of the organizations eliminated creativity (Dessler, 2009).

\section{Practices of the Creative Behavior}

Since creative behavior refers to the activity or distinguished behavior perpetrated by an individual or the group in the workplace and embodied in 
one or more of the behaviors or practices, the practices of the creative behavior includes the following (Al-Qahtani, 2002):

- The organization adoption of the change and its contribution to its publication within.

- Using or employing a new methods and modalities in the work.

- Reject the monotony in the work and lack of acceptance of the practices, or to obey orders that restrict the individual's thinking.

- The ability to adapt, being flexible in the workplace, contribute to solving problems, and to take risks.

\section{Previous Studies}

- Study of Judipat and Tarela (2015), entitled: Creativity and Organizational Citizenship Behavior in the Nigerian Hospitality Industry.

The study aimed to identify the relationship between the creativity opportunity and the organizational citizenship behavior in the Nigerian hospitality industry. The cross sectional survey was carried out with a sample size of 1450 employee derived from a population of 3768 employee. The scales used in the framework accepted the Cronbach's alpha values, which have been interpreted to be trusted. After the completion of auditing the questionnaires and counting the good ones for the statistical analysis of the 1093 questionnaire, the descriptive statistics indicators were calculated in the first phase of the analysis. On the other hand, the spearman correlation coefficient was used in the second phase of the analysis.

The study results showed that the opportunity for the creativity is closely linked with the altruistic, conscience, civic virtue, from the courtesy and sportsmanship. The results indicate that organizations conditions are ready for the creativity and serves as additional enhancement to the employee's behavior.

- Study of Al-Saudi (2012), entitled: The Impact of Organizational Climate upon the Innovative Behavior at Jordanian Private Universities as Perceived by Employees.

The study aimed to identify the impact of the organizational climate on the creative behavior in the Jordanian private universities. To achieve the purposes of this study, a questionnaire was developed and distributed to 841 employees. 612 questionnaires were retrieved, and the data were analyzed using the Statistical Package for Social Sciences (SPSS) in order to process the study data. The results indicate that the perception level among the respondents about the organizational climate dimensions was medium, while their perceptions level about the innovation behavior was high. In addition, the study discovered the existence of a statistically significant impact for the organizational climate dimensions on the innovation behavior. The study 
recommends the need to promote and develop the staff and the allocation of sufficient funds to support the creativity of employee in Jordan.

- Study of Al-Shmoot (2011), entitled: Impact of the work environment on the administrative creativity: An applied study on Academy of Saad Al-Abed Allah for Security Sciences in Kuwait.

The study aimed to identify the impact of the work environment on the administrative creativity: An applied study on Academy of Saad Al-Abed Allah for Security Sciences in Kuwait. However, this study was conducted through achieving a number of objectives including; determining the level of the work environment importance at the academy, determine the level of administrative creativity, and determine the impact of work environment factors on the administrative creativity in the Academy. Therefore, the study reached a number of the following most important results:

a. Existence of a statistically significant impact for the organizational structure on administrative creativity (creative behavior and creative abilities).

b. Existence of a statistically significant impact for the regulations and directives on administrative creativity (creative behavior and creative abilities).

c. Existence a statistically significant impact for the participation in decision-making on administrative creativity (creative behavior and creative abilities).

- Study of Qudsiat (2010), entitled: The organizational culture and its impact on the administrative creativity from the perspective of the employees in nursing profession at hospital of the founder of King Abdullah University.

The study aimed to identify the organizational culture and its impact on the administrative creativity from the perspective of the employees in nursing profession at hospital of the founder of King Abdullah University. Also, the study aimed to analyze the relationship between the organizational culture elements (beliefs, values and norms, expectations) and the administrative creativity level (solving the problem and decision-making, spirit of risk-taking, encouragement of creativity, ability to change). In addition, it aims to check the availability of the organizational culture elements, and identify the level of administrative creativity areas. Furthermore, it aims to ascertain whether there were statistically significant differences at the significance level $(\alpha=0.05)$, in the respondents' responses attributable to the personal and functional characteristics for employers (gender, age, educational level, service years, monthly income, functional level, and number of employees in the department). This was done on the administrative creativity level and the organizational culture elements (administration anticipating from the individual, organizational norms, organizational values, organizational beliefs, individual anticipating from the administration). 
Consequently, the results also show that the overall level of the administrative creativity for the employees as a whole was medium degree. Hence, the administrative creativity areas were arranged in descending order according to the arithmetic means as follows: solving the problem and decision-making, spirit of risk-taking, ability to change, and encouragement of creativity.

- Study of Al-Zouabi (2009), entitled: Impact of the organizational culture on creativity: An applied study in the Jordanian pharmaceutical companies.

The study aimed to identify the relationship between the organizational culture and the demographic characteristics and its impact on the achievement of creativity among the employees, as well as to identify the extent of a discrepancy in the creativity level among the employees attributed to the variation in their demographics. The study shows that there is a statistically significant impact for each dimension of the organizational culture (objectives values, values of the support and encouragement, discipline values, and the free style values) in the ability of the employees on creativity.

\section{Method and procedures}

\section{The Study Approach}

Based on the study objectives, the researcher adopted a descriptive approach to describe the study variables from the perspective of the employees in the commercial banks operating in Jordan. Also, the study used the analytical approach to analyze the impact of the organizational culture on creative behavior.

\section{The Study Population and its Sample}

The study population consists of all the commercial banks operating in Jordan. Due to large study population size, the researcher has resorted to select a sample of these banks. Hence, the study sample consists of 300 employees, selected according to stratified random sample method. After that, the researcher distributed 300 questionnaires to the study sample. 260 questionnaires were returned, where the percentage of questionnaires returned is $86.7 \%$. After the reviewed and audited questionnaires were returned, 10 questionnaires were excluded due to the lack of the information contained in each. As a result, the number of valid questionnaires for statistical analysis was 250 questionnaires, while the percentage of the valid questionnaires for analysis from the distributor number is $83.3 \%$.

\section{The Study Tool}

To achieve the study objectives, the researcher prepares and develops a study tool based on the administrative literature, previous studies related to 
the organizational culture, and the creative behavior. The adoption of a scale to measure the study variables are divided into three levels. Here, the calculated cut-off grade is obtained by dividing the difference between the highest value of the likert scale (5) and the lowest value (1) at the three levels. The cut-off grade is expressed as: $\{(1-5) / 3=1.33\}$. Thus, the three levels as follows:

a. Low applying: (1-2.33).

b. Medium applying: (2.34-3.67).

c. High applying: (3.68-5).

After that, the tool was used to measure sincerity and its reliability as follows:

\section{a. Tool Sincerity}

The face validity of the questionnaire has been verified. This was done through the presentation to a group of arbitrators with expertise and knowledge from teaching faculty members at Zarqa University of administrative sciences, scientific research methodology. The aim of the arbitration is to verify the extent of items belonging to the study variables, which is an appropriate degree of drafting items. The questionnaire included in its final form 30 items distributed on the independent and dependent variables.

\section{b. Tool Reliability}

To check the questionnaire reliability, the stability coefficient was calculated for the tool (the internal consistency of the questionnaire items) using Cronbach's Alpha coefficient. Thus, the reliability coefficient for the overall tool is 0.865 , and the Cronbach's Alpha coefficients values are statistically acceptable especially in the administrative, behavioral, and educational researches when these values are within the range $(0.60-0.75)$. However, this can be seen in Table 1 below:

Table 1. Results of reliability (Internal Consistency of the items)

\begin{tabular}{|c||c||c||c||}
\hline The Variables & $\mathrm{N}$ & Cronbach's Alpha & Stability Ratio \\
\hline \hline Work teams & 5 & 0.692 & $\% 69.2$ \\
\hline The ability to adapt & 5 & 0.607 & $\% 60.7$ \\
\hline The ability to innovate & 5 & 0.604 & $\% 60.4$ \\
\hline Solving the problems & 5 & 0.734 & $\% 73.4$ \\
\hline Change susceptibility & 5 & 0.748 & $\% 74.8$ \\
\hline Contact amplitude & 5 & 0.646 & $\% 64.6$ \\
\hline \hline Overall Tool & 30 & 0.865 & $\% 86.5$ \\
\hline
\end{tabular}

\section{Results and discussion}

This section aims to present the statistical analysis results of the data related to the employees' responses about the study question, and the statistical analysis results of testing the hypotheses, which was reached through the use 
of Statistical Package for Social Sciences (SPSS). Therefore, the results of this study were classified as follows:

\section{Results Related to $1^{\text {st }}$ Question}

What is the application level of the organizational culture dimensions in the commercial banks from the perspective of their employees?

To answer the $1^{\text {st }}$ question, the means and standard deviations were calculated to identify the employees' estimates in the commercial banks operating in Jordan. This was about the level of their evaluation for the organizational culture dimensions (work teams, the ability to adapt, and the ability to innovate). Therefore, this can be seen in Table 2 below:

Table 2. Means and standard deviations for the Organizational Culture dimensions

\begin{tabular}{|l|l||l|l||l|l|}
\hline No. & $\begin{array}{l}\text { Organizational Culture } \\
\text { Dimensions }\end{array}$ & Mean & $\begin{array}{l}\text { Std. } \\
\text { Dev. }\end{array}$ & Rank & $\begin{array}{l}\text { Evaluation } \\
\text { level }\end{array}$ \\
\hline \hline 1 & Work teams & 4.38 & 0.38 & 1 & High \\
\hline 2 & The ability to adapt & 4.32 & 0.46 & 3 & High \\
\hline 3 & The ability to innovate & 4.33 & 0.39 & 2 & High \\
\hline
\end{tabular}

The results in Table 2 indicate that the means of the organizational culture dimensions (work teams, the ability to adapt, and the ability to innovate) equals to $4.38,4.32$, and 4.33 respectively. Thus, all the means is larger than the test criteria, 3 out of 5 on a Likert Scale. These results show employees at the commercial banks operating in Jordan. A clear vision about the importance of these dimensions indicates that the evaluation was positive, and this means that the commercial banks are applying the mentioned dimensions with High degree from the perspective of the employees.

Also, the results indicate to get work teams dimension on the (first) rank in terms of its importance of the employees in the commercial banks operating in Jordan, with mean (4.38) and standard deviation (0.38); the ability to innovate dimension came in the (second) rank, with mean (4.33) and standard deviation (0.39); and finally, the ability to adapt dimension came in the (third) rank on the ladder of priorities of the employees' estimates in the mentioned banks, with mean (4.32) and standard deviation (0.46).

\section{Results Related to $2^{\text {nd }}$ Question}

What is the evaluation level of the employees in the commercial banks for the creative behavior dimensions?

To answer the $2^{\text {nd }}$ question, the means and standard deviations has been calculated to identify the employees' estimates in the commercial banks operating in Jordan on the level of their evaluation for the creative behavior dimensions which include solving the problems, change susceptibility, and contact amplitude. Thus, this is as shown in the Table 3 below: 
Table 3. Means and standard deviations for the Creative Behavior dimensions

\begin{tabular}{|c|c|c|c|c|c|}
\hline No. & $\begin{array}{l}\text { Creative Behavior } \\
\text { Dimensions }\end{array}$ & Mean & $\begin{array}{l}\text { Std. } \\
\text { Dev. }\end{array}$ & Rank & $\begin{array}{c}\text { Evaluation } \\
\text { level }\end{array}$ \\
\hline 1 & Solving the problems & 4.13 & 0.64 & 3 & High \\
\hline 2 & Change susceptibility & 4.29 & 0.46 & 1 & High \\
\hline 3 & Contact amplitude & 4.19 & 0.55 & 2 & High \\
\hline
\end{tabular}

The results in Table (3), indicates that the means of the creative behavior dimensions (solving the problems, change susceptibility, contact amplitude) equals to $4.13,4.29$, and 4.19 respectively. Hence, all the means are larger than the test criteria 3 of 5 on a Likert Scale. These results show the employees at the commercial banks operating in Jordan. A clear vision on the importance of these dimensions indicates that the evaluation was positive, with High degree from the perspective of the employees in the commercial banks operating in Jordan.

Also, the results indicate to get change susceptibility dimension on the (first) rank in terms of its importance of the employees in the commercial banks operating in Jordan, with mean (4.29) and standard deviation (0.46); contact amplitude dimension came in the (second) rank, with mean (4.19) and standard deviation (0.55); and finally solving the problems dimension came in the (third) rank on the ladder of priorities of the employees' estimates in the mentioned banks, with mean (4.13) and standard deviation (0.64).

\section{Results of Testing the Study Hypothesis \& its Sub-hypotheses}

Before testing the study hypothesis, some tests to be made on the study data must be verified. These tests are:

\section{a. Variance Inflation Factors -VIF:}

This test was used to verify whether Multicollinearity existed between the independent variables or not. Table 4 below shows the results of VIF:

Table 4. Results of VIF test to verify of the Multicollinearity between the Organizational Culture dimensions

\begin{tabular}{||c||c||c||c||}
\hline \hline No. & Organizational Culture Dimensions & Tolerance & VIF \\
\hline \hline 1 & Work teams & 0.675 & 1.482 \\
\hline 2 & The ability to adapt & 0.774 & 1.292 \\
\hline 3 & The ability to innovate & 0.674 & 1.483 \\
\hline
\end{tabular}

\section{[The critical value of $($ VIF $)=10]$.}

The results listed in table (4) show that there is no Multicollinearity between the independent variables. This is asserted by the values of VIF for the organizational culture dimensions (work teams, the ability to adapt, and the ability to innovate) which are $1.482,1.292$, and 1.483 respectively. Here, all these values are lower than the critical value of the test which is 10 . 


\section{b. One-Sample t-Test}

This test was used to validate the homogeneity of the data. Table 5 shows the results of One-Sample t-Test:

Table 5. Results of One-Sample t-Test

\begin{tabular}{||c||c||c||c||c||}
\hline No. & Study Variables & t-values & df. & Sig. \\
\hline \hline 1 & Work teams & 57.926 & 249 & 0.000 \\
\hline 2 & The ability to adapt & 45.298 & 249 & 0.000 \\
\hline 3 & The ability to innovate & 64.872 & 249 & 0.000 \\
\hline 4 & Solving the problems & 27.823 & 249 & 0.000 \\
\hline 5 & Change susceptibility & 43.996 & 249 & 0.000 \\
\hline 6 & Contact amplitude & 33.875 & 249 & 0.000 \\
\hline
\end{tabular}

[The critical value of $(t)$ with $(d f .=249)$ and $(\alpha=0.05)=1.96$ ]

According to the table 5, the results showed that the study data was characterized by high homogeneity. This could be proved by (t) values of $57.926,45.298,64.872,27.823,43.996$, and 33.875 of the work teams, the ability to adapt, the ability to innovate, solving the problems, change susceptibility, and contact amplitude respectively. Here, all these values are more than the critical value (t) (1.96).

\section{c. Sampling Adequacy}

The results in table 6 show KMO test to verify the suitability of the property method of selecting a sample study and adequacy of data. Thus, this was done using Kaiser-Meyer-Olkin scale as follows:

Table 6. Results of KMO test in verifying Sampling Adequacy

\begin{tabular}{|c||c|}
\hline Statistical measures & Tolerance \\
\hline \hline KMO & 0.787 \\
\hline Sig. (P-value) & 0.000 \\
\hline
\end{tabular}

The result described in the table 6 shows that the selected sample is sufficient and appropriate for the purposes of the statistical analysis. This is supported by the value of the KMO test amounting to 0.787 , which is greater than the half (0.5). On the other hand, the value of the statistical significance (Sig.) is less than the significance level $(\alpha=0.05)$.

After being sure to verify some of the aforementioned characteristics of data, it was possible to test the study hypothesis and their sub-hypotheses as follows:

\section{Results of Testing the Main Hypothesis}

Ho: There is no statistically significant impact at the significant level $(\alpha \leq 0.05)$, for the organizational culture dimensions (work teams, the ability to adapt, and the ability to innovate), on the creative behavior of the employees at the commercial banks operating in Jordan. 
In order to test the validity of the study hypothesis, the stepwise multiple linear regression analysis was used. Thus, this is as shown in table 7 and 8 below:

Table 7. Summary of the Multiple Linear Regression Model

\begin{tabular}{|c||c||c||c||c||c||}
\hline $\mathrm{R}$ & $\mathrm{R}^{2}$ & $\mathrm{~F}_{\text {Ratio }}$ & Sig. & df. & Tabulated (F) \\
\hline \hline 0.656 & 0.431 & 61.991 & 0.000 & $(3,246)$ & 2.60 \\
\hline
\end{tabular}

\section{Dependent Variable: Creative behavior}

The results in table 7 show that:

a. Validity of multiple linear regressions is proven. This is asserted by the calculated value $(F)(61.991)$ which is greater than 2.60, and the significance value $(0.000)$ which is less than the significance level $(\alpha=0.05)$.

b. The value of the $\mathrm{R}^{2}$ of 0.431 , refers to the organizational culture dimensions (work teams, the ability to adapting, and the ability to innovate), which interprets the percentage $(43.1 \%)$ of the changes in the creative behavior of the employees at the commercial banks operating in Jordan.

Table 8. Results of the Stepwise Multiple Linear Regression Analysis to measure the impact of the organizational culture dimensions on the creative behavior

\begin{tabular}{||c||c||c||c||c||}
\hline $\begin{array}{c}\text { Organizational Culture } \\
\text { Dimensions }\end{array}$ & $\begin{array}{c}\text { Coefficients } \\
(\beta)\end{array}$ & $\begin{array}{c}\text { Standard } \\
\text { Error }\end{array}$ & (t) value & Sig. \\
\hline \hline Constant $\left(\beta_{0}\right)$ & -0.107 & 0.323 & -0.332 & 0.740 \\
\hline Work teams & 0.380 & 0.071 & 5.361 & 0.000 \\
\hline The ability to innovate & 0.377 & 0.082 & 4.575 & 0.000 \\
\hline The ability to adapt & 0.234 & 0.054 & 4.341 & 0.000 \\
\hline
\end{tabular}

The results in table 8 show that the statistical significant of regression coefficients $(\beta)$ for the dimensions (work teams, the ability to adapt, and the ability to innovate) was proven. Therefore, there exist a statistically significance impact at the significant level $(\alpha=0.05)$ for the above dimensions on the creative behavior of the employees at the commercial banks operating in Jordan. Depending on the statistical significant values and all the values less than the significant level $(\alpha=0.05)$, it was found that the (work teams) dimension is the most influential on the creative behavior at a rate effect which is totaled 0.380. This, however, means that the null hypothesis $\left(\mathrm{H}_{0}\right)$ is rejected.

\section{Results of Testing the $1^{\text {st }}$ Sub-hypothesis}

Ho1: There is no statistically significant impact at the significant level ( $\alpha \leq 0.05$ ), for the organizational culture dimensions (work teams, the ability to adapting, and the ability to innovate), on solving the problems at the commercial banks operating in Jordan. 
In order to test the validity of the study hypothesis, the stepwise multiple linear regression analysis was used. Thus, this is as shown in table 9 and 10 below:

Table 9. Summary of the Multiple Linear Regression Model

\begin{tabular}{|c||c||c||c||c|c||}
\hline \hline $\mathrm{R}$ & $\mathrm{R}^{2}$ & $\mathrm{~F}_{\text {Ratio }}$ & Sig. & df. & Tabulated (F) \\
\hline \hline 0.648 & 0.420 & 59.461 & 0.000 & $(3,246)$ & 2.60 \\
\hline
\end{tabular}

\section{Dependent Variable: Solving the Problems}

The results in table (9) show that:

a. Validity of multiple linear regressions is proven. This is asserted by the calculated value $(\mathrm{F})(59.461)$ which is greater than 2.60, and the significance value $(0.000)$ which is less than the significance level $(\alpha=0.05)$.

b. The value of the $\mathrm{R}^{2}$ of 0.420 refers to the organizational culture dimensions (work teams, the ability to adapt, and the ability to innovate), and it interprets the percentage $(42 \%)$ of the changes in solving the problems at the commercial banks operating in Jordan.

Table 10. Results of the Stepwise Multiple Linear Regression Analysis to measure the impact of the organizational culture dimensions on solving the problems

\begin{tabular}{|c|c|c|c|c|}
\hline $\begin{array}{c}\text { Organizational Culture } \\
\text { Dimensions }\end{array}$ & $\begin{array}{l}\text { Coefficients } \\
\qquad(\beta)\end{array}$ & $\begin{array}{l}\text { Standard } \\
\text { Error }\end{array}$ & (t) value & Sig. \\
\hline Constant $\left(\beta_{0}\right)$ & -1.851 & 0.459 & -4.031 & 0.000 \\
\hline The ability to innovate & 0.792 & 0.117 & 6.765 & 0.000 \\
\hline The ability to adapt & 0.385 & 0.077 & 5.022 & 0.000 \\
\hline Work teams & 0.202 & 0.101 & 2.009 & 0.046 \\
\hline
\end{tabular}

The results in table 8 show that the statistical significant of regression coefficients $(\beta)$ for the dimensions (work teams, the ability to adapt, and the ability to innovate) is proven. Therefore, there exist a statistically significance impact at the significant level $(\alpha=0.05)$ for the above dimensions on solving the problems at the commercial banks operating in Jordan. Depending on the statistical significant values and all the values less than the significant level $(\alpha$ $=0.05$ ), the ability to innovate dimension was found as the most influential on the solving the problems at a rate effect totaled 0.792 . Therefore, this means that the null hypothesis $\left(\mathrm{H}_{01}\right)$ is rejected.

\section{Results of Testing the $2^{\text {nd }}$ Sub-hypothesis}

Ho2: There is no statistically significant impact at the significant level ( $\alpha \leq 0.05$ ), for the organizational culture dimensions (work teams, the ability to adapt, and the ability to innovate), on change susceptibility in the commercial banks operating in Jordan. 
In order to test the validity of the study hypothesis, the stepwise multiple linear regression analysis was used. Thus, this can be seen in Table 11 and 12 below:

Table 11. Summary of the Multiple Linear Regression Model

\begin{tabular}{|c||c||c||c||c||c||}
\hline $\mathrm{R}$ & $\mathrm{R}^{2}$ & $\mathrm{~F}_{\text {Ratio }}$ & Sig. & df. & Tabulated (F) \\
\hline \hline 0.506 & 0.256 & 42.546 & 0.000 & $(2,247)$ & 3.00 \\
\hline
\end{tabular}

\section{Dependent Variable: Change susceptibility}

The results in table 11 show that:

a. Validity of multiple linear regressions is proven. This is asserted by the calculated value $(\mathrm{F})(42.546)$ which is greater than 3.00 , and the significance value (0.000) is less than the significance level $(\alpha=0.05)$.

b. The value of the $\mathrm{R}^{2}$ of 0.256 refers to the organizational culture dimensions (work teams, and the ability to innovate), and it interprets the percentage $(25.6 \%)$ of the changes in change susceptibility at the commercial banks operating in Jordan.

Table 12. Results of the Stepwise Multiple Linear Regression Analysis to measure the impact of the organizational culture dimensions on change susceptibility

\begin{tabular}{|c|c|c|c|c|}
\hline $\begin{array}{c}\text { Organizational Culture } \\
\text { Dimensions }\end{array}$ & Coefficients $(\beta)$ & $\begin{array}{l}\text { Standard } \\
\text { Error }\end{array}$ & (t) value & Sig. \\
\hline Constant $\left(\beta_{0}\right)$ & 0.986 & 0.367 & 2.683 & 0.008 \\
\hline Work teams & 0.409 & 0.079 & 5.149 & 0.000 \\
\hline The ability to innovate & 0.349 & 0.092 & 3.780 & 0.000 \\
\hline
\end{tabular}

The results in the table 12 show that the statistical significant of regression coefficients $(\beta)$ for two dimensions (work teams, and the ability to innovate) is proven. Therefore, there exist a statistically significance impact at the significant level $(\alpha=0.05)$ for the above dimensions on change susceptibility at the commercial banks operating in Jordan. Depending on the statistical significant values and all the values less than the significant level ( $\alpha$ $=0.05$ ), it was found that the (work teams) dimension is the most influential on the change susceptibility at a rate effect totaled 0.409 . This means that the null hypothesis $\left(\mathrm{H}_{02}\right)$ is rejected.

While not practiced, the (ability to adapting) dimension have a clear impact on the change susceptibility at the commercial banks operating in Jordan, which is supported by the statistical significance value of the mentioned dimension which amounted to 0.279 . Hence, this is greater than the significance level $(\alpha=0.05)$.

\section{Results of Testing the $3^{\text {rd }}$ Sub-hypothesis}

Ho3: There is no statistically significant impact at the significant level $(\alpha \leq 0.05)$, for the organizational culture dimensions (work teams, the ability 
to adapt, and the ability to innovate), on contact amplitude at the commercial banks operating in Jordan.

In order to test the validity of the study hypothesis, the stepwise multiple linear regression analysis was used. This is as shown in table 13 and 14 below:

Table 13. Summary of the Multiple Linear Regression Model

\begin{tabular}{||c||c||c||c||c||c||}
\hline $\mathrm{R}$ & $\mathrm{R}^{2}$ & $\mathrm{~F}_{\text {Ratio }}$ & Sig. & df. & Tabulated (F) \\
\hline \hline 0.505 & 0.255 & 42.224 & 0.000 & $(2,247)$ & 3.00 \\
\hline
\end{tabular}

\section{Dependent Variable: Contact amplitude}

The results in table 13 show that:

a. Validity of simple linear regression is proven. This is asserted by the calculated value $(\mathrm{F})(42.224)$ which is greater than 3.00, and the significance value $(0.000)$ is less than the significance level $(\alpha=0.05)$.

b. The value of the $\mathrm{R}^{2}$ of 0.255 refers to the organizational culture dimensions (work teams, and the ability to adapting), which interprets the percentage $(25.5 \%)$ of the changes in contact amplitude at the commercial banks operating in Jordan.

Table 14. Results of the Stepwise Multiple Linear Regression Analysis to measure the impact of the organizational culture dimensions on contact amplitude

\begin{tabular}{||c||c||c|c||c||}
\hline $\begin{array}{c}\text { Organizational Culture } \\
\text { Dimensions }\end{array}$ & $\begin{array}{c}\text { Coefficients } \\
(\beta)\end{array}$ & $\begin{array}{c}\text { Standard } \\
\text { Error }\end{array}$ & (t) value & Sig. \\
\hline \hline Constant $\left(\beta_{0}\right)$ & 0.655 & 0.386 & 1.700 & 0.090 \\
\hline Work teams & 0.557 & 0.089 & 6.280 & 0.000 \\
\hline The ability to adapt & 0.252 & 0.072 & 3.494 & 0.001 \\
\hline
\end{tabular}

The results in the table 14 show that the statistical significance of regression coefficients $(\beta)$ for two dimensions (work teams, and the ability to adapting) is proven. Therefore, there exist a statistically significance impact at the significant level $(\alpha=0.05)$ for the above dimensions on contact amplitude at the commercial banks operating in Jordan. Depending on the statistical significant values and all the values less than the significant level $(\alpha=0.05)$, the (work teams) dimension was found as the most influential on the change susceptibility at a rate effect totaled 0.557 . Thus, this means that the null hypothesis $\left(\mathrm{H}_{03}\right)$ is rejected.

While not practiced, the (ability to innovate) dimension has a clear impact on the change susceptibility at the commercial banks operating in Jordan, which is supported by the statistical significance value of the mentioned dimension that amounted to 0.887 . Thus, this is greater than the significance level $(\alpha=0.05)$. 


\section{Conclusions and recommendations Conclusions} conclusions:

In light of the previous results, the study adopts the following

- Rising the means of the organizational culture dimensions (work teams, the ability to adapt, and the ability to innovate). These results indicate that the employees' responses at the commercial banks operating in Jordan about these dimensions were positive. Also, this means that the evaluation level of these dimensions was high from their perspective. The work teams got on the first rank in light perceptions of the study sample. Thus, this is due to the fact that the mentioned commercial banks encourages this type of human relations.

-Rising the means of the creative behavior dimensions (solving the problems, change susceptibility, contact amplitude). These results indicate that the employees' responses at the commercial banks operating in Jordan on these dimensions was positive. Also, this means that the evaluation level of these dimensions was high from their perspective. The change susceptibility got on the first rank in light perceptions of the study sample, and is due to the fact that the mentioned commercial banks have possess the will for change in accordance with the developments.

- There exist a statistically significance impact at the significant level $(\alpha=0.05)$, for the organizational culture dimensions (work teams, ability to adapt, and ability to innovate), on the creative behavior of the employees at the commercial banks operating in Jordan.

- There exist a statistically significance impact at the significant level ( $\alpha=0.05$ ), for the organizational culture dimensions (work teams, ability to adapt, and ability to innovate), on solving the problems at the commercial banks operating in Jordan.

- There exist a statistically significance impact at the significant level $(\alpha=0.05)$, for two dimension of the organizational culture dimensions (work teams, and ability to innovate), on change susceptibility at the commercial banks operating in Jordan.

- There exist a statistically significance impact at the significant level $(\alpha=0.05)$, for two dimension of the organizational culture dimensions (work teams, and ability to adapt), on contact amplitude at the commercial banks operating in Jordan.

\section{Recommendations}

In light of the conclusions reached by this study, the researcher recommends the following:

- Necessity interest of the commercial banks administrations operating in Jordan by the (ability to adapt) dimension as one of the organizational 
culture dimensions because it got on the (third) rank in light of the employees' responses in the mentioned banks.

- Interest of the commercial banks administrations operating in Jordan (solving the problems) as one of the creative behavior dimensions because it got on the (third) rank on the priorities ladder of the employees in the mentioned banks.

- Necessity interest of the commercial banks administrations operating in Jordan to make some appropriate adjustments to the internal regulations, legislation, and instructions. It should pass a notice to their employees that there a possibility of change in order to raise the ability of the employees to adapt.

- The work to encourage the creative ideas through the commercial banks operating in Jordan improve the incentives and rewards law, monitors award to the distinguished employees and innovators, and acquaint them with the required interest and care.

- The researcher proposes doing studies in the future to be used by another variable. This is different from the variables addressed in the current study, taking into account the application of other statistical methods of processing the data, which will be performed in the future.

\section{References:}

Angelo. J. (2002). The Organization Culture Perspective, Chicago, Deros Press.

Al-Saudi \& Mousa A. (2012). Impact of Organizational Climate upon the Innovative Behavior at Jordanian Private Universities as Perceived by Employees: A Field Study, International Business and Management, 5(2): 1427.

Al-Ahmad \& Hussam (2008). Impact of the Organizational Culture in the Development of the Creative Behavior of Employees, Master Thesis (Unpublished), University of Aleppo, Syria.

Al-Khalifa \& Ziyad Saeed (2008). The Organizational Culture and its Role in Raising the Performance Level: A survey on the Officers of Command and Staff College of the Saudi Armed Forces, Master Thesis (Unpublished), An electronic copy, Naif University for Security Sciences, Riyadh, Saudi Arabia. Al-Zouabi \& Hassan Ali (2009). Impact of the Organizational Culture in the Creativity: An Applied Study in the Jordanian pharmaceutical Companies, Master Thesis (Unpublished), Umm Al-Qura University, Saudi Arabia.

Al-Emmyan \& Mahmoud (2009). The Organizational Behavior in the Business Organizations, Dar Wael for Publishing and Distribution, Amman, Jordan.

Al-Aajez, Fouad Ali, \& Assaf Mahmoud Abdul Majeed (2007). The Social Role of the Director of the High School in Gaza and its Relationship to the 
Organizational Culture in the Light of the Quality Principles, Research Presented to the $3^{\text {rd }}$ Educational Conference for the period (November 17-18), Gaza, Palestine.

Al-Faraaj \& Osama (2011). A proposed Model to the Characteristics of the Appropriate Organizational Culture in the Public Sector Institutions, Journal of Economics and Juridical Sciences, 27(1): 155-184.

Al-Qaryouti \& Mohammad Qasim (2000). The Organizational Behavior, $3^{\text {rd }}$ Edition, Dar Al-ShuroK for Publishing, Amman, Jordan.

Al-Qahtani \& Salem (2002). The Organizational Obstacles to Creativity at Administrative Development Employees in the government Bodies in Saudi Arabia, Journal of Administrative Sciences, 14 (2).

Dessler \& Gary (2011). Human Resources Management, 12th Edition, Person Education limited.

Dessler \& Gary (2009). Human Resources Management, Translation Ahmed Sayed Mohamed Abdel Mutaal and Abdul Mohsen Abdul Mohsen Juodeh, Dar Al-Mriekh, Riyadh, Saudi Arabia.

Al-Shmoot \& Ahmed Saad (2011). Impact of the Work Environment on the Administrative Creativity, An Applied Study on Academy of Saad Al-Abed Allah for Security Sciences in Kuwait, Master Thesis (Unpublished), University of the Middle East, Faculty of Business, Jordan.

Gerinberg, Njirak, Baron, \& Robert (2004). The Behavior Management in the Organizations. Translation Rifay, and Basiouni, Ismail, Dar Al-Mriekh, Riyadh, Saudi Arabia, p. 631.

Judipat N.O. \& Tarela, O. (2015). Creativity and Organizational Citizenship Behavior in the Nigerian Hospitality Industry, International Journal of Managerial Studies and Research, 3(3): 9-20.

Najem \& Abboud Najem (2007). The Innovation Management: Concepts and Characteristics and Modern Experiences, Dar Wael for Publishing and Distribution, Amman, Jordan.

Qudsiat \& Reem Ibrahim (2010). The Organizational Culture and its Impact on the Administrative Creativity from the perspective of the Employees in Nursing Profession at Hospital of the Founder of King Abdullah University, Master Thesis (Unpublished), University of Yarmouk, Jordan.

Roos \& Wanda (2005). The Relationship between Employees' motivation, Job Satisfaction and Corporate Culture, Master of Science, University of South Africa.

Zhao \& Fang (2005). Exploring the Synergy between Entrepreneurship and Innovation, International Journal of Entrepreneurial Behavior \& Research, 11(1): 25-41. 